\title{
Ethics of mitigation, adaptation and geoengineering
}

\author{
Bert Gordijn · Henk ten Have
}

Published online: 5 January 2012

(C) Springer Science+Business Media B.V. 2011

There are currently three ways of attempting to tackle climate change. The two conventional approaches are mitigation and adaptation. Mitigation is here understood as involving efforts to cut emissions of global greenhouse gases. In contrast, adaptation entails measures to minimize the harmful effects of climate change. Next to these two traditional approaches, a new method of dealing with climate change has now entered the limelight, albeit still in an embryonic stage of technological development: geoengineering. The signatories of the Kyoto Protocol-adopted in 1997 and entered into force in 2005-have agreed to significantly reduce anthropogenic emissions of greenhouse gases. As yet, however, few countries have completely met their mitigation targets. As a result, there is growing concern that current mitigation efforts might not be adequate in order to prevent perilous climate change levels. Unquestionably, actions aimed at reducing the vulnerability to dangerous climate change effects, are going to be indispensable in order to lessen the most detrimental impacts. However, these adaptation measures are likely to be very expensive. Against this backdrop, geoengineering has been advanced as a deliberate and possibly costeffective scheme of large-scale management of the planetary climate. All three approaches currently on hand trigger their own distinct set of ethical issues.

\section{Mitigation}

It is increasingly becoming apparent that mitigation attempts might not be really successful anytime soon. So

B. Gordijn $(\bowtie) \cdot$ H. ten Have

Dublin, Ireland

e-mail: bert.gordijn@dcu.ie far, many rich countries seem to be unwilling or are unable to carry through radical measures to hold back greenhouse gas emissions. Surely some of them fear mitigation might negatively affect economic growth and material welfare. As a result, many people, especially in the poorest countries in the world, have experienced and will increasingly encounter adverse climate change effects on health, both in terms of morbidity and mortality (Patz et al. 2005 and McMichael et al. 2006). Kicking the can down the road in relation to mitigation, however, also means that future generations will have to bear the brunt of climate change. This triggers intricate questions of intergenerational justice. Finally, there is increasing concern about biodiversity disruption and loss, which might be caused by climate change as well (Dawson 2011). In short, our lack of success to curb greenhouse gas emissions seems to be compromising the right to life, liberty and security of person (Art. 3, Universal Declaration of Human Rights 1948), especially in poorer countries. Our current behaviour also seems incongruous with our responsibility of ensuring that the needs and interests of future generations be fully safeguarded (Art. 1, Declaration on the Responsibilities of the Present Generations towards Future Generations 1997). At last, it might turn out to be hard to reconcile with our obligations with regard to biodiversity conservation (Art. 8 \& 9, Convention on Biological Diversity 1992).

\section{Adaptation}

At first sight the distribution of the burdens and benefits of anthropogenic climate change seems to be unfair. The poorest countries, having contributed least to the problem of global warming, are affected most severely by its adverse effects. To many this appears to be a significant 
global injustice. As a result there is a broad agreement that richer countries, having mostly contributed to global warming, have an obligation to support poorer nations in their adaptation measures. The precise extent to which richer countries can be held historically responsible and accountable for current climate impacts, however, is not easy to determine. Against this backdrop, intricate debates are currently emerging about the fairness of distribution of costs and benefits of prevention and adaptation measures, the responsibility for compensation for residual damages, and procedural questions about fair participation in the related decision processes (Grasso 2010).

\section{Geoengineering}

Against the backdrop of our seeming inability to effectively address the problem of global warming by political means, think tanks, NGOs and policymakers alike are more and more seriously debating 'geoengineering', the deliberate large-scale manipulation of the Earth's climate (see for example ETC Group 2010; UK House of Commons 2010; GAO 2011; Umweltbundesamt 2011). 'Geoengineering' is a term for a variety of divergent technologies that are in most cases still technologically immature. At present, there are two dominant geoengineering approaches on hand: Carbon Dioxide Removal and Solar Radiation Management. The first approach endeavors to reduce the concentration of carbon dioxide in the atmosphere, e.g. by enhancing the biological or chemical sinks of atmospheric carbon dioxide. The second method seeks to reflect solar radiation, for example, by injecting aerosols into clouds or by introducing large amounts of sulphur dioxide into the stratosphere, thereby restricting the amount of radiation absorbed by the Earth's surface and thus lowering the global mean temperature.

Proponents of further development and possible future deployment of geoengineering claim it might be the only way to avoid climate catastrophe, if we continue to be unable to significantly cut down greenhouse gas emissions through bold policy initiatives. However, even if we were able to achieve success in mitigation in the short term, we might already have passed certain tipping points. In this situation, greenhouse gas emissions alone might not suffice to reverse the change. Thus we might still need geoengineering interventions to prevent disaster. Finally, geoengineering might provide us with much needed extra time in order to launch effective mitigation and adaptation schemes.

Opponents argue that geoengineering might lead to conflicts, a fatal arms race or even the destabilization of the
Earth's climate. In addition, the 'technological fix' does not address the root cause of anthropogenic global warming and could subvert any further political mitigation efforts ('moral hazard'). Whilst possibly providing an effective approach to reducing adverse effects of global warming, geoengineering might thus open up a Pandora's Box of new undesirable quandaries.

Global warming and the different approaches of dealing with it - mitigation, adaptation and geoengineering — prompt intricate ethical questions to do with global and intergenerational justice and health. Europe has demonstrated climate policy leadership with regard to mitigation and adaptation. It will now have to develop a stance toward geoengineering as well, as will every other country in the world. Because of its conflict potential and dual use character an internationally coordinated approach seems particularly imperative in relation to geoengineering. This approach will have to be informed by solid ethical analysis of the underlying questions. Against this backdrop, the editors invite more contributions dealing with issues at the interface of climate change policy, justice and health. The very first paper of the current issue is an excellent start of a much needed debate (Lacey 2012).

\section{References}

Dawson, T.P. 2011. Beyond predictions: Biodiversity conservation in a changing climate. Science 332(53): 52-58.

ETC. Group. 2010. Retooling the planet: Climate chaos in the geoengineering age. Swedish Society for nature conservation.

GAO. 2011. Climate engineering: Technical status, future directions and potential responses. Report from the Center for Science, Technology and Engineering, United States Government Accountability Office. GAO-11-71.

Grasso, M. 2010. An ethical approach to climate adaptation finance. Global Environmental Change 20(1): 74-81.

Lacey, J. 2012. Climate change and Norman Daniels' theory of just health: An essay on basic needs. Medicine, Health Care and Philosophy (this issue).

McMichael, A.J., R.E. Woodruff, and S. Hales. 2006. Climate change and human health: Present and future risks. Lancet 367: 859-869.

Patz, J.A., D. Campbell-Lendrum, T. Holloway, and J.A. Foley. 2005. Impact of regional climate change on human health. Nature 436: 310-317.

UK House of Commons. 2010. Science and Technology Committee. The Regulation of Geoengineering. HC 221, Fifth Report of Session 2009-10.

Umweltsbundesamt. 2011. Geo-engineering: Wirksamer Klimaschutz oder Größenwahn? [Geoengineering: Effective climate protection or megalomania? Report by the German Federal Environment Agency].

US House of Representatives. 2010. Committee on Science and Technology. Engineering the climate: research needs and strategies for international coordination. One hundred eleventh congress, Second session, October 2010. 